\title{
IDENTIFIKASI BAKTERI Escherichia PADA IKAN SELAR (Selaroides sp.) BAKAR DI BEBERAPA RESTO DI KOTA MANADO
}

\author{
Laydy Francesca H. Laluraa, Helen J. Lohoo dan Hanny W. Mewengkang \\ Fakultas Perikanan dan Ilmu Kelautan, Universitas Sam Ratulangi, Manado, Sulawesi Utara.
}

\begin{abstract}
ABSTRAK
Tujuan penelitian ini adalah untuk mengidentifikasi bakteri Escherichia pada ikan selar (Selaroides sp.) bakar yang ada di beberapa resto di kota Manado. Pada identifikasi bakteri Escherichia pada ikan selar bakar digunakan beberapa metode identifikasi seperti uji pewarnaan gram, uji moyiliti, uji katalase, uji oksidase, uji IMViC dan uji fermentasi karbohidrat ( fruktosa, laktosa, sukrosa, maltose, glukosa). Hasil analisa presumptive coliform berkisar antara $9,3 \times 10^{1}-2,4 \times 10^{3} \mathrm{MPN} / 100 \mathrm{~g}$ dan rata-rata koloni pada EMB Agar untuk total e. colli $1,3 \times 10^{2}-9,7 \times 10^{3}$ MPN/100g dan total coliform $1,2 \times 10^{3}$ TBUD, dan untuk identifikasi sifat bakteri pada uji IMViC menggunakan acuan dari SNI 01-2897-1992.
\end{abstract}

Kata kunci: Ikan selar, Escherichia, Manado.

\section{PENDAHULUAN}

Ikan merupakan bahan pangan yang mudah mengalami kerusakan biologis oleh enzim atau mikro organisme pembusuk, sehingga memerlukan penanganan yang khusus untuk mempertahankan mutunya. Proses kerusakan ikan berlangsung lebih cepat di daerah tropis, karena suhu dan kelembaban harian yang tinggi. Proses kemunduran mutu tersebut makin dipercepat dengan cara penanganan atau penangkapan yang kurang baik, fasilitas sanitasi yang tidak memadai serta terbatasnya sarana distribusi dan pemasaran (Widiastuty, 2008).

Proses pembusukan ikan dapat disebabkan terutama oleh aktivitas enzim yang terdapat di dalam tubuh ikan sendiri, aktivitas mikro organisme, atau proses oksidasi pada lemak tubuh oleh oksigen dari udara. Kelemahan-kelemahan yang dimiliki oleh ikan telah dirasakan sangat menghambat usaha pemasaran hasil perikanan dan tidak jarang menimbulkan kerugian besar, terutama pada saat produksi ikan melimpah (Afrianto dan Liviawaty, 1989).

Bakteri merupakan salah satu organisme mikroskopik yang dapat menimbulkan penyakit (Infeksi) pada manusia. Meskipun pada umumnya jenis bakteri yang merugikan jumlahnya lebih sedikit dari jumlah keseluruhan spesies bakteri yang ada di dunia, akan tetapi karena bersifat pathogen, maka dapat sangat mengganggu kehidupan, kesehatan dan bahkan dalam keadaan akut dapat menyebabkan kematian manusia (Adji, 2008).
Bakteri Escherichia merupakan bakteri yang dapat hidup pada usus hewan mamalia termasuk manusia. Penyebaran kotoran baik manusia dan hewan yang tidak terkontrol dalam lingkungan perairan dapat menyebabkan lingkungan perairan tercemar oleh bakteri ini. Bakteri Escherichia juga banyak mengkontaminasi ikan-ikan segar dan ini sangat membahayakan jika ikan segar yang sudah terkontaminasi oleh bakteri Escherichia dikonsumsi oleh konsumen. Bakteri Escherichia yang mengkontaminasi ikan-ikan segar sumber utamanya adalah air, dan penanganan ikan yang kurang baik.

Kota Manado terkenal dengan kota yang menyediakan makanan laut, dan sangat banyak rumah makan di Manado yang menyediakan menu makanan laut. Contohnya adalah menu ikan Tude atau Oci bakar. Menu ini sangat digemari konsumen, baik konsumen lokal maupun mancanegara. Menu ini digemari karena selain rasanya yang enak juga harganya yang relatif terjangkau.

Kegemaran makan ikan tude atau oci bakar tersebut tentu saja menuntut teknik penanganan dan pengolahan yang saniter dan higiene dari pengolahannya. Berdasarkan hal tersebut penulis merasa perlu melakukan penelitian tentang bakteri Escherichia pada ikan selar (Selaroides sp.) bakar di beberapa rumah makan di Manado. Penelitian ini bertujuan mengidentifikasi bakteri Escherichia pada ikan Selar bakar yang ada di beberapa rumah makan di kota Manado. Penelitian ini diharapkan dapat memberikan informasi yang bermanfaat bagi 
pengolah rumah makan dan konsumen ikan Selar bakar khususnya mengenai bakteri Escherichia.

\section{METODOLOGI PENELITIAN}

\section{Bahan Baku dan Alat}

Bahan baku penelitian ini adalah ikan selar bakar dan ikan selar segar sebagai pembanding. Bahan kimia yang digunakan adalah akuades, alkohol, peptone, lugol, yeast ekstrak, Nutrient Agar (NA), Nutrient Broth (NB), NaCl, Kristal violet, Lugol, Safranin, Motility Test Medium, Glukosa, Laktosa, Maltose, Sukrosa, Kovac's Reagen, Metil Red, Larutan $\mathrm{H} 2 \mathrm{O} 2$.

Alat yang digunakan adalah kotak pendingin, Autoclave, Inkubator, Oven, Mikroskop, Cawan petri, Erlenmeyer, Pipet, Timbangan analitik, $\mathrm{pH}$ meter, Tabung reaksi, Gelas ukur, Tabung durham, Lampu spirtus, Kaca objek, Pingset, Pisau, Jarum ose, Magnetic stirrer, Kompor listrik, Pipet tetes, Thermometer, Aluminium foil, Korek api, Kamera digital, Alat tulis menulis, Plastik wraping, Masker, Handscone, Baju laboratorium.

\section{Tata Laksana Penelitian}

Sampel diambil dari 3 rumah makan yang sudah ditentukan, pada masing-masing rumah makan dilakukan dua kali pengambilan sampel dengan jarak pengambilan kurang lebih 1 minggu. Jumlah ikan yang diambil setiap pengambilan masing-masing 2 ekor ikan bakar dan 2 ekor ikan segar. Dengan rata-rata berat ikan 70-100 gram, panjang $15-30 \mathrm{~cm}$.

Sampel ikan selar bakar yang sudah dibakar oleh karyawan didinginkan dahulu lalu dimasukkan dalam plastik dan ditaruh dalam kotak pendingin untuk mencegah kontaminasi. Dan ikan selar segar diambil langsung dari tempat penyimpanan ikan segar dan dimasukkan dalam plastik dan ditaruh dalam kotak pendingin. Adapun uji mikrobiologis yang dilakukan menggunakan metode dimodifikasi oleh Ijong (2003).

Isolasi dan penyedian kultur sediaan dilakukan dengan menyeleksi koloni bebas yang tumbuh pada media EMBA dan diinkubasi selama $24-48$ jam dengan suhu $37^{\circ} \mathrm{C}$.

Identifikasi didasarkan pada hasil uji biokimia yang meliputi uji pewarnaan Gram, uji Motility, Katalase, oksidase, IMViC dan Fermentasi Karbohidrat (Cappucino dan Sherman, 1992).

\section{HASIL DAN PEMBAHASAN}

Manado menunjukkan jumlah total coliform yang cukup tinggi. Hal ini dapat berhubungan dengan tingkat kontaminasi pada tempat penyimpanan ikan segar, air yang dipakai untuk mencuci ikan, penanganan selama ikan dibakar dan sesudah dibakar. Hasil analisa Total Coliform pada ikan Selar secara rinci ditampilkan pada Tabel 6 .

Dari hasil nilai Presumptive pada coliform dapat dilihat adanya kontaminasi pada ikan selar bakar, dan kita bisa melihat nilai rata-rata jumlah coliform dan E.coli pada media biakkan EMB agar pada Tabel 7.

Kontaminasi pada ikan bakar disebabkan penangan ikan pada saat pembakaran, tempat pemanggang ikan, wadah ikan bakar yang sudah masak yang tidak diperhatikan kebersihannya. Kontaminasi ini biasa disebut kontaminasi silang, kontaminasi yang disebabkan oleh bahan non pangan.

Dari hasil rata-rata jumlah mikroba pada ikan selar bakar yang lebih banyak atau lebih besar jumlahnya daripada ikan segar, ini menyatakan bahwa penanganan ikan selama di bakar kurang baik atau tidak dapat penanganan secara higienis, dan itu menyebabkan ikan selar bakar yang akan dikonsumsi oleh konsumen menjadi tidak layak untuk dikonsumsi.

Kontaminasi yang terjadi pada ikan selar bakar diakibatkan penanganan pada saat penyimpanan, pengasapan atau pembakaran ikan yang tidak bersih. Alat pembakaran ikan yang tidak bersih adalah salah satu penyebab ikan bakar tersebut terkontaminasi, karena pada tiga rumah makan tempat pengambilan sampel tempat pembakaran ikan yang dipakai tidak bersih, meja yang menjadi tempat untuk menempatkan ikan yang sudah dalam wadah setelah selesai dibakar juga tidak bersih tidak memenuhi aturan sanitasi alat pengolahan ikan yang harus bersih.

Menurut Faridz, dkk., (2007), kontaminasi bakteri pada makanan atau pada alat-alat pengolahan merupakan suatu indikasi bahwa praktek sanitasi dalam suatu industri kurang baik.

Bahan pangan (ikan selar) dapat tercemar oleh mikroba sebelum pengolahan (pencemaran primer) atau selanjutnya sesudah pengolahan (pencemaran sekunder). Kebiasaan pribadi para pekerja dan konsumen dalam mengelolah bahan pangan dapat merupakan sumber yang penting dari pencemaran sekunder (Faridz, $d k k$., 2007). 
Tabel 1. Hasil Analisa Presumptive Coliform

\begin{tabular}{|c|c|c|c|}
\hline Resto & Ulangan & Sampel & $\begin{array}{c}\text { Presumptive Coliform } \\
\text { (MPN/100g) }\end{array}$ \\
\hline \multirow{8}{*}{ A } & \multirow{4}{*}{1} & KS & $2.4 \times 10^{2}$ \\
\hline & & $\mathrm{BS}$ & $2.4 \times 10^{2}$ \\
\hline & & KB & $2.4 \times 10^{2}$ \\
\hline & & BB & $2.3 \times 10^{1}$ \\
\hline & \multirow{4}{*}{2} & KS & $2.9 \times 10^{2}$ \\
\hline & & BS & $2.4 \times 10^{3}$ \\
\hline & & $\mathrm{KB}$ & $9.3 \times 10^{1}$ \\
\hline & & BB & $2.4 \times 10^{3}$ \\
\hline \multirow{8}{*}{ B } & \multirow{4}{*}{1} & KS & $2.4 \times 10^{3}$ \\
\hline & & BS & $2.9 \times 10^{2}$ \\
\hline & & KB & $9.3 \times 10^{1}$ \\
\hline & & $\mathrm{BB}$ & $2.4 \times 10^{3}$ \\
\hline & \multirow{4}{*}{2} & KS & $2.4 \times 10^{3}$ \\
\hline & & $\mathrm{BS}$ & $2.4 \times 10^{3}$ \\
\hline & & KB & $2.4 \times 10^{3}$ \\
\hline & & BB & $2.4 \times 10^{3}$ \\
\hline \multirow{9}{*}{$\mathrm{C}$} & \multirow{4}{*}{1} & KS & $2.4 \times 10^{3}$ \\
\hline & & BS & $2.9 \times 10^{2}$ \\
\hline & & $\mathrm{KB}$ & $2.4 \times 10^{3}$ \\
\hline & & $\mathrm{BB}$ & $2.4 \times 10^{3}$ \\
\hline & \multirow{5}{*}{2} & $\mathrm{KS}$ & $2.4 \times 10^{3}$ \\
\hline & & BS & $4.6 \times 10^{2}$ \\
\hline & & KB & $2.4 \times 10^{3}$ \\
\hline & & $\mathrm{BB}$ & \\
\hline & & & $2.4 \times 10^{3}$ \\
\hline
\end{tabular}

Kontaminasi yang diakibatkan para pekerja adalah kebiasan sehari-hari pekerja yang tidak bersih.Kalau dilihat di resto tempat pengambilan sampel, kontaminasi yang disebakan oleh pekerja juga termasuk salah satu penyebabnya.Pekerja ketika membakar ikan, mereka tidak menggunakan sarung tangan yang bersih.

Tangan yang dipakai memegang kain lap untuk mengangkat tempat pembakaran ikan dipakai untuk memegang ikan untuk dimasukkan dalam plastik sampel atau meletakkan ikan bakar di piring untuk penyajian, pekerja memakai penjepit ikan yang juga tidak bersih, sudah dipakai berulang-ulang dan penjepit yang hanya diletakkan ditempat yang tidak bersih.

Menurut Nastiti, (2006), dalam proses pengasapan resiko yang timbul dapat disebabkan karena kepekatan panggang yang tidak terkontrol atau terukur. Ikan yang telah selesai dipanggang diletakkan di tempat yang tidak tertutup atau kurang higienis. Biasanya ikan olahan yang sudah jadi ditempatkan di keranjang yang terbuat dari bambu dan tidak tertutup. Sama halnya pada tempat pengambilan sampel di tiga resto tersebut, pada proses penanganan ikan yang telah selesai dibakar sangat tidak higienis, ikan hanya dibiarkan di tempat atau wadah yang terbuka. Dengan penanganan yang tidak higienis ini yang menyebabkan pertumbuhan mikroba infestasi lalat/serangga.

Tabel 2. Jumlah Rata-Rata Koloni Pada EMB Agar

\begin{tabular}{|c|c|c|c|c|}
\hline Resto & Ulangan & Sampel & $\begin{array}{c}\Sigma \\
\text { E.coli } \\
\text { (cfu/g) }\end{array}$ & $\begin{array}{c}\Sigma \\
\text { Coliform } \\
(\mathbf{c f u} / \mathbf{g})\end{array}$ \\
\hline \multirow[t]{8}{*}{ A } & \multirow[t]{4}{*}{1} & KS & $4.0 \times 10^{3}$ & $2.2 \times 10^{3}$ \\
\hline & & BS & - & $2.3 \times 10^{3}$ \\
\hline & & $\mathrm{KB}$ & $8.6 \times 10^{2}$ & $2.7 \times 10^{3}$ \\
\hline & & $\mathrm{BB}$ & - & $1.6 \times 10^{3}$ \\
\hline & \multirow[t]{4}{*}{2} & $\mathrm{KS}$ & $1.1 \times 10^{3}$ & $2.8 \times 10^{3}$ \\
\hline & & BS & $8.3 \times 10^{2}$ & $2.0 \times 10^{3}$ \\
\hline & & $\mathrm{KB}$ & - & TBUD \\
\hline & & $\mathrm{BB}$ & $2.7 \times 10^{3}$ & $1.6 \times 10^{3}$ \\
\hline \multirow[t]{8}{*}{ B } & \multirow[t]{4}{*}{1} & KS & $1.6 \times 10^{3}$ & $7.3 \times 10^{3}$ \\
\hline & & BS & $4.6 \times 10^{2}$ & TBUD \\
\hline & & $\mathrm{KB}$ & $1.0 \times 10^{3}$ & $3.9 \times 10^{3}$ \\
\hline & & $\mathrm{BB}$ & $2.1 \times 10^{3}$ & $1.2 \times 10^{3}$ \\
\hline & \multirow[t]{4}{*}{2} & KS & $5 \times 10^{2}$ & TBUD \\
\hline & & BS & $7.3 \times 10^{2}$ & TBUD \\
\hline & & $\mathrm{KB}$ & $2.6 \times 10^{3}$ & $5.8 \times 10^{3}$ \\
\hline & & BB & $1.5 \times 10^{3}$ & $4.8 \times 10^{3}$ \\
\hline \multirow[t]{8}{*}{$\mathrm{C}$} & \multirow[t]{4}{*}{1} & KS & $9.7 \times 10^{3}$ & $2.7 \times 10^{3}$ \\
\hline & & BS & $4 \times 10^{2}$ & TBUD \\
\hline & & KB & $9.6 \times 10^{2}$ & $4.9 \times 10^{3}$ \\
\hline & & $\mathrm{BB}$ & $1.3 \times 10^{2}$ & TBUD \\
\hline & \multirow[t]{4}{*}{2} & KS & $8 \times 10^{2}$ & $3.7 \times 10^{3}$ \\
\hline & & BS & $5.1 \times 10^{3}$ & $1.4 \times 10^{3}$ \\
\hline & & $\mathrm{KB}$ & $1.3 \times 10^{3}$ & $2.3 \times 10^{3}$ \\
\hline & & BB & $2.5 \times 10^{3}$ & $1.1 \times 10^{3}$ \\
\hline
\end{tabular}

Menurut Yahono, (2004), teknik pengasapan tradisional biasanya menggunakan peralatan yang sederhana, tanpa adanya pertimbangan untuk menjaga mutu ikan sebagai bahan pangan mentah dengan standar sanitasi dan higienis yang sangat rendah. Konsekuensinya produk akhir tidak menarik bentuk maupun penampilannya, tidak merangsang selera, dan bahkan tidak cocok untuk digunakan sebagai makanan.

Yang seharusnya ikan selar dibakar untuk mempertahankan mutu ikan dalam bentuk pengolahan, tidak menjadi layak untuk dikonsumsi atau mutu menurun karena pada saat pengolahan ikan tidak mendapat penanganan secara benar. Ikan harus diperhatikan sebagaimana bahan makanan yang lain. Kebersihan harus selalu dijaga sepanjang rantai distribusi, mengingat bahwa ikan adalah bahan makanan yang lebih cepat membusuk daripada yang lain. Selain ikan itu sendiri, alatalat yang digunakan dalam penanganan harus pula diperhatikan kebersihannya ( Murniayati dan Sunarman, 2000).

\section{KESIMPULAN}

Berdasarkan SNI Batas maksimum cemaran mikroba dalam pangan, jumlah bakteri 
pada ikan bakar/asap sudah melewati batas maksimum. Ikan yang cemaran mikroba melewati batas maksimum tidak baik untuk di konsumsi. Dari hasil identifikasi jenis-jenis mikroba coliform yang teridentifikasi, yaitu Escherichia coli, Enterobacter sp, dan Klebsiela.

\section{DAFTAR PUSTAKA}

Adji, K. 2008. Evaluasi Kontaminasi Bakteri Patogen Pada Ikan Segar di Perairan Teluk Semarang.Tesis. Manajemen Sumberdaya Pantai. Universitas Diponegoro. Semarang

Afrianto E. dan E. Liviawati. 1989. Pengawetan dan Pengolahan Ikan.Kanisius. Yokyakarta.

Faridz, R., Hafiluddin, Mega Ansahari. 2007. Analisis Jumlah Bakteri dan Keberadaan Escherichia coli Pada Pengolahan Ikan Teri Nasi di PT. Kelola Mina Laut
Unit. Sumenap. Jurnal Embryo Vol 4 No 2. Teknologi Industri Pertanian Fakultas Pertanian Unijoyo

Ijong, F, G. 2003. Uji IMVIC. Uraian Teoritis Proses Biokimianya. Laboratorium Mikrobiologi Hasil Perikanan. FPIK Unsrat

Murniyati, A,S., Sunarman. 2000. Pendinginan dan Pengawetan. Kanisius. Jakarta

Nastiti D. 2006. Kajian Penentuan Mutu Produk Ikan Manyung (Arius thalassinus) Panggang di Kota Semarang. Tesis Manajemen Sumber Daya Pantai. Universitas Diponegoro. Semarang

Widiastuty, I., 2008. Analisis Mutu Ikan Tuna Selama Lepas Tangkap Perbedaan Preparasi dan Waktu Penyimpanan. Institut Pertanian Bogor.

Yahono, S.B. 2004. Kajian Beberapa Aspek Pengolahan Ikan Secara Tradisional Dalam Upaya Peningkatan Mutu Produk Perikanan di Kabupaten Jepara. Tesis Manajemen Sumber Daya Pantai. Pasca Sarjana Universitas Diponegoro. Semarang 